\title{
A case series of surgically diagnosed idiopathic aortitis in a Canadian centre: a retrospective study
}

\author{
Diane L. Murzin MD, Eric C. Belanger MD, John P. Veinot MD, Nataliya Milman MD; \\ for the Canadian Vasculitis Network (CanVasc)
}

\section{Abstract}

Background: Idiopathic aortitis became recognized relatively recently, and the body of knowledge concerning this condition is scarce. We aimed to determine the frequency of idiopathic aortitis in aortic specimens, the clinical, laboratory and radiologic characteristics at diagnosis and during follow-up, and the approach to investigation, treatment and monitoring taken by the treating physicians.

Methods: We identified cases of aortitis diagnosed on pathological specimens of the aorta between Jan. 1, 2003, and July 31, 2013, at The Ottawa Hospital by reviewing the hospital's pathology database. Charts of identified patients were reviewed, and data on patient demographic characteristics, clinical features, laboratory and imaging tests, treatment and outcomes were analyzed.

Results: A total of 684 aortic specimens were analyzed during the study period; 47 cases of aortitis were identified, 32 of which were idiopathic. Twenty-one patients (66\%) had complete imaging of branch vessels at baseline, $16(76 \%)$ of whom had additional aortic or branch vessel lesions. Twelve patients (38\%) received corticosteroids postoperatively. Over a mean follow-up period of 47.5 months, among the 12 patients (38\%) who had complete imaging of branch vessels at least once, new aortic or branch lesions were diagnosed in 5 (42\%); $3 / 32$ patients (9\%) required additional vascular surgery; and a new systemic condition was diagnosed in 2/32 (6\%).

Interpretation: Idiopathic aortitis is commonly discovered incidentally on examination of the pathological specimen following ascending aortic aneurysm repair. No guidelines exist for the investigation, treatment and follow-up of this condition, resulting in great variability of practice. Good-quality prospective studies are needed to address the many unanswered clinical questions regarding idiopathic aortitis and to allow formulation of more definitive recommendations.

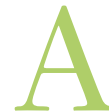

ortitis is a general term used to describe inflammation of the aorta. ${ }^{1}$ It is known to be associated with a variety of systemic vasculitides (most commonly giant cell arteritis ${ }^{2,3}$ and Takayasu's arteritis $\left.{ }^{3,4}\right)$, other systemic inflammatory diseases such as rheumatoid arthritis, ${ }^{5}$ systemic lupus erythematosus, ${ }^{6}$ ankylosing spondylitis ${ }^{7}$ and infections (especially bacterial infections, syphilis ${ }^{8}$ and tuberculosis $^{9}$ ). In a substantial fraction of cases, aortitis is diagnosed in patients with no history or clinical symptoms of a systemic disease. ${ }^{10-12}$ Although some of these cases may be a sequela of a clinically unapparent or burned-out systemic condition causing few or no symptoms ${ }^{13}$ when no such condition is apparent, the term idiopathic aortitis is used.

Idiopathic aortitis is currently a poorly defined entity, and all of the current knowledge about the condition comes from retrospective series of cases with pathologically identified aortitis. ${ }^{10-12}$ The largest of these series is from the Mayo Clinic (an older series of 45 cases of aortitis, 21 of which were classified as idiopathic, ${ }^{10}$ and a more recent series of 64 patients with 52 cases of idiopathic aortitis ${ }^{11}$ ) and the Cleveland Clinic (an older series of 52 cases of aortitis, 36 of which were classified as idiopathic, ${ }^{12}$ and a recent unpublished report of 196 cases, including 129 cases of idiopathic aortitis $\left.{ }^{14}\right)$. We conducted a review to determine 1) the frequency of idiopathic aortitis among aortic specimens at The Ottawa Hospital (TOH) over a 10.5-year period, 2) the clinical, biochemical and radiographic characteristics of idiopathic aortitis, 3) the approach to investigation, treatment and follow-up taken by the treating physicians and 4) long-term outcomes.

\section{Methods}

We performed a retrospective review at $\mathrm{TOH}$, a tertiary care teaching hospital affiliated with the University of Ottawa Heart Institute, which is a referral centre for cardiovascular diseases for 40 centres throughout Ontario. We identified cases for this study from the TOH pathology database, which contains records of all histologic analyses performed at $\mathrm{TOH}$ and the

Competing interests: None declared.

This article has been peer reviewed.

Correspondence to: Nataliya Milman, nmilman@toh.on.ca

CMAJ Open 2017. DOI:10.9778/cmajo.20160094 
University of Ottawa Heart Institute. We searched the database records of specimens analyzed between Jan. 1, 2003, and July 31, 2013, for the terms "aorta," "aortic" and "aortitis." We reviewed identified records and selected cases of aortitis, defined as active inflammation of the aortic wall that involves the media and/or intima..$^{15}$ Atherosclerosis was excluded. Because the specific patterns of inflammation in aortic specimens are not discriminative between aortitis of different causes, ${ }^{15}$ we included all patterns of aortic inflammation and classified cases based on clinical information rather than histologic appearance.

We reviewed the TOH charts (electronic medical records and paper charts) of patients with identified cases of histologic aortitis for demographic characteristics, clinical information and available biochemical and radiographic investigations. Duration of follow-up was determined based on the last clinical encounter recorded at TOH. We classified cases into 3 groups: 1) infectious aortitis, when culture or special staining of the aortic specimen (performed in selected cases) showed the presence of an infectious organism or when evidence of active systemic infection was documented at the time of aortic surgery, 2) secondary aortitis, when a diagnosis of a systemic inflammatory condition known to be associated with aortitis was documented within 1 year of the diagnosis of aortitis, and 3) idiopathic aortitis, when no infectious agent or associated systemic condition could be identified. Cases of idiopathic aortitis in which detailed imaging of the aortic branch vessels did not reveal abnormalities were further classified as isolated aortitis, in accordance with the most recent nomenclature of vasculitides. ${ }^{16}$ Cases in group 3 (idiopathic aortitis and isolated aortitis) constituted the focus of the current study.

\section{Statistical analysis}

We employed descriptive statistics to summarize the outcomes using Microsoft Office Excel 2011.

\section{Ethics approval}

This project was approved by the Ottawa Health Science Network Research Ethics Board.

\section{Results}

Aortic specimens from 684 patients were analyzed at TOH during the study period. We identified 47 cases of aortitis, for an incidence of aortitis in patients undergoing aortic or cardiac surgery at TOH of $6.9 \%$. Of the 47 cases, $7(15 \%)$ were infectious (6 bacterial endocarditis and 1 due to nontuberculous mycobacteria). Of the 40 cases of noninfectious aortitis, 32 (80\% of noninfectious cases and $68 \%$ of all aortitis cases) were idiopathic (6 of which could be further classified as isolated aortitis) and 8 (20\% of noninfectious cases and $17 \%$ of all aortitis cases) were secondary. The associated systemic conditions in the 8 cases of secondary aortitis were giant cell arteritis in 5 cases (isolated in 3 , with polymyalgia rheumatica in 1 and with rheumatoid arthritis in 1) and, in 1 case each, isolated polymyalgia rheumatica, Takayasu's arteritis and rheumatoid arthritis. The incidence of noninfectious, idiopathic and isolated aortitis in our cohort was $5.8 \%, 4.7 \%$ and $0.9 \%$, respectively.

\section{Characteristics at diagnosis of aortitis}

Baseline characteristics of the 32 patients with idiopathic aortitis are presented in Table 1. Their mean age was 66.0 (standard deviation 12.7) years (range 17-83 yr), and 18 (56\%) were female (Table 1). Most presented with aneurysm-related symptoms such as chest pain and dyspnea (12 patients [38\%]) or incidentally discovered aneurysm on imaging or echocardiography (14 [44\%]). Other presentations included abdominal pain, weakness and lower extremity claudication. For 3 patients (9\%), the presentation was unknown.

The surgical procedures that led to the diagnosis of aortitis

\section{Table 1: Baseline characteristics of patients with idiopathic} aortitis

\begin{tabular}{|c|c|}
\hline Characteristic & $\begin{array}{c}\text { No. }(\%) \text { of patients } \\
n=32\end{array}$ \\
\hline Age, mean \pm SD (range), yr & $\begin{array}{l}66.0 \pm 12.7 \\
(17-83)\end{array}$ \\
\hline Female sex & $18(56)$ \\
\hline \multicolumn{2}{|l|}{ Smoking status } \\
\hline At/before diagnosis & $22(69)$ \\
\hline Never & $4(12)$ \\
\hline Unknown & $6(19)$ \\
\hline \multicolumn{2}{|l|}{ Comorbidity at diagnosis } \\
\hline Hypertension & $20(62)$ \\
\hline Dyslipidemia & $14(44)$ \\
\hline Coronary artery disease & $14(44)$ \\
\hline $\begin{array}{l}\text { Cerebrovascular accident/transient } \\
\text { ischemic attack }\end{array}$ & $5(16)$ \\
\hline Diabetes mellitus & $4(12)$ \\
\hline Chronic renal failure & $2(6)$ \\
\hline \multicolumn{2}{|l|}{ Medications at diagnosis } \\
\hline Acetylsalicylic acid & $31(97)$ \\
\hline Other antiplatelet & $3(9)$ \\
\hline $\begin{array}{l}\text { Angiotensin-converting-enzyme } \\
\text { inhibitor/angiotensin II receptor } \\
\text { blocker }\end{array}$ & $18(56)$ \\
\hline$\beta$-blocker & $27(84)$ \\
\hline Statin & $12(38)$ \\
\hline$\geq 1$ antihypertensive & $30(94)$ \\
\hline \multicolumn{2}{|l|}{ Inflammatory markers } \\
\hline $\begin{array}{l}\text { Erythrocyte sedimentation rate, mean } \\
\pm \mathrm{SD} \text { (range), } \mathrm{mm} / \mathrm{hr}(n=12)\end{array}$ & $\begin{array}{l}41.0 \pm 19.2 \\
\quad(5-75)\end{array}$ \\
\hline $\begin{array}{l}\text { C-reactive protein level, mean } \pm \text { SD } \\
\text { (range), } \mathrm{mg} / \mathrm{L}(n=9)\end{array}$ & $\begin{array}{l}82.8 \pm 62.0 \\
(6.6-179.0)\end{array}$ \\
\hline $\begin{array}{l}\text { Presence of additional radiographic } \\
\text { lesions in patients with full imaging } \\
(n=21)\end{array}$ & $16(76)$ \\
\hline Aortic lesions & $3(14)$ \\
\hline Branch lesions & $15(71)$ \\
\hline
\end{tabular}


were complex surgeries performed by cardiac and/or vascular surgeons that combined resection or repair of a thoracic aneurysm or dilatation, aortic valve replacement or repair, and/or coronary artery bypass grafting in all but 2 patients (who had a simple aortic valve replacement and coronary artery bypass grafting, respectively). In 23 patients (72\%), the source of the histologic diagnosis of aortitis was a thoracic aortic aneurysm or dilatation; in the remaining 9 patients (28\%), histologic evidence of aortitis came from sections of aortic tissue obtained during aortic valve replacement and/or coronary artery bypass grafting.

Erythrocyte sedimentation rate and/or C-reactive protein level were measured in 13 patients; 10 (77\%) had a significantly elevated erythrocyte sedimentation rate $(>30 \mathrm{~mm} / \mathrm{hr}$ ) or C-reactive protein level or both.

\section{Imaging findings}

Computed tomography was the most common modality for preoperative imaging of idiopathic aortitis, performed in 25 patients (78\%). Five patients (16\%) were assessed with echocardiography, and imaging modality was not documented for 2 (6\%).

Of 23 aneurysms related to idiopathic aortitis, all but 1 involved the ascending aorta (Figure 1). Six were limited to the ascending aorta, and the rest had variable degrees of proximal and distal extension (with 2 spanning the whole length of the aorta, from ascending to abdominal); 1 aneurysm was limited to the aortic arch.

Twenty-one patients (66\%) had complete imaging of the aortic branch vessels at baseline. Branch vessel lesions were found in 15 patients (71\%), and additional aortic lesions were found in 3 (14\%) (2 of whom also had branch vessel involvement) (Table 2).

\section{Medical treatment}

Twelve patients (38\%), including 2 of the 6 with isolated aortitis, received treatment with glucocorticoids postoperatively. There was substantial variability in both the initial dosage of prednisone (range 20-100 mg/d) and the duration of treatment (range $2.5 \mathrm{wk}$ to $>9 \mathrm{yr}$ ); the definitive stop date was known for only 3 patients.
Three patients also received methotrexate. One of the 3 was reported to be taking methotrexate for rheumatoid arthritis 8 years after diagnosis of idiopathic aortitis; the rheumatoid arthritis had been diagnosed during that year by a community rheumatologist. The reason for use of methotrexate in the remaining 2 patients, at 5 months and 13 months, respectively, after aortitis was diagnosed, was unknown.

\section{Outcomes}

The mean duration of follow-up was 47.5 (standard deviation 33.2) months (range 1-123 mo). Computed tomography and echocardiography were the most common modalities used for follow-up imaging, having been performed in 23 patients (72\%) and 10 patients $(31 \%)$, respectively (some patients had imaging with both modalities). Seven patients had further imaging with magnetic resonance angiography (3 patients), conventional aortography (1 patient) or positron emission tomography (3 patients).

Twelve patients (38\%) had complete imaging of branch vessels at least once during follow-up. Table 2 details the number and location of additional aortic and branch lesions. New lesions were found in $5 / 12$ patients ( $42 \%$ ) 3 months to 8 years following surgery; none of the patients with new lesions at follow-up were initially classified as having isolated aortitis.

Development of additional radiographic lesions at followup did not differ significantly by treatment status. Of the 12 patients who had complete follow-up imaging, $6(50 \%)$ received glucocorticoids postoperatively; delayed lesions developed in 3 of the treated and 2 of the untreated patients. Notably, 10 of the 12 patients with complete follow-up imaging and all 5 patients with new lesions had additional branch lesions at the time of diagnosis of idiopathic aortitis.

Three patients had additional surgical procedures during the follow-up period: 2 required endovascular stenting of the thoracic aorta at the site of initial surgery 2 and 4 months, respectively, after their original aortic surgeries, and a patient with isolated aortitis, who had 2 distinct aortic lesions, under-

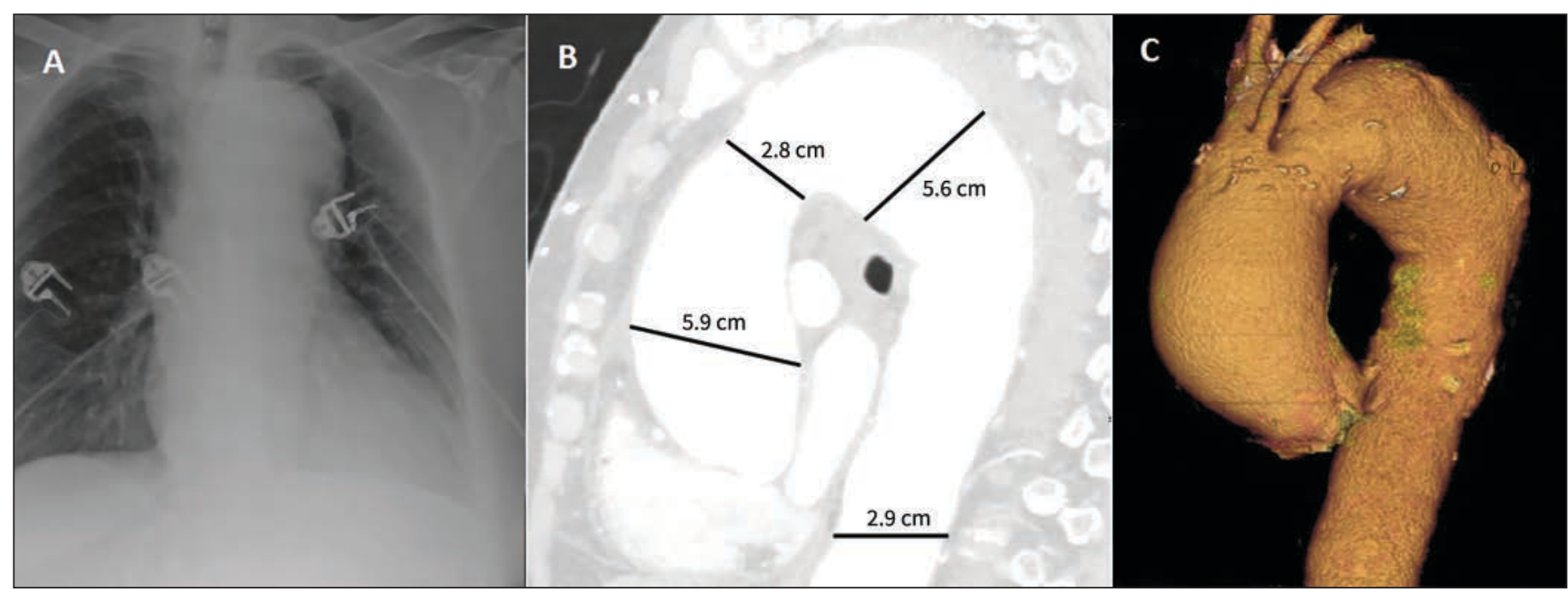

Figure 1: Baseline imaging of a patient with idiopathic aortitis. (A). Plain chest radiograph. (B). Contrast-enhanced computed tomography scan. (C). Three-dimensional (3D) reconstruction. All panels show diffuse involvement of thoracic aorta, with maximum dimensions indicated on panel B. There is also dilatation of the origins of the brachiocephalic and left subclavian arteries, visible on 3D reconstruction (panel C). 


\begin{tabular}{|c|c|c|}
\hline \multirow[b]{2}{*}{ Location } & \multicolumn{2}{|c|}{ No. of patients } \\
\hline & $\begin{array}{l}\text { Before/at diagnosis of aortitis } \\
\qquad n=21\end{array}$ & $\begin{array}{l}\text { At follow-up } \\
\quad n=12\end{array}$ \\
\hline Aorta/branch & 16 & 5 \\
\hline Aorta & $\begin{array}{l}3 \text { (isolated in } 1 \text {, and with additional branch } \\
\text { lesions in 2) } \\
\text { - Abdominal aortic aneurysm } 1 \\
\text { - Residual type B dissection } 1 \\
\text { - Distal abdominal aortic stenosis } 1\end{array}$ & $\begin{array}{l}3 \text { (all with additional branch lesions) } \\
\text { - Abdominal aortic aneurysm } 2 \\
\text { - Increased aortic wall thickness } 1\end{array}$ \\
\hline Branch & $\begin{array}{l}\text { 15 } \\
\text { Carotid stenosis }<50 \% 5 \\
\text { Arch branch dilatation } 11 \text { (7 patients) } \\
\text { - Right innominate } 5 \\
\text { - Carotid } 2 \\
\text { - Subclavian } 3 \\
\text { - All vessels (spontaneous resolution) } 1 \\
\text { Arch branch thickening } 1 \\
\text { Left internal carotid artery occlusion } 1 \\
\text { lliac stenosis } 2 \\
\text { Dissection } 2 \\
\text { - Common iliac 1 } \\
\text { - Left subclavian 1 }\end{array}$ & \begin{tabular}{l}
\multicolumn{1}{c}{5} \\
Arch branch dilatation 3 \\
- Right innominate 1 \\
- Carotid 1 \\
- Subclavian 1 \\
Left common iliac artery dissection 1 \\
Left common iliac artery aneurysm 1
\end{tabular} \\
\hline
\end{tabular}

went open thoracoabdominal aneurysm repair 31 months after the original aortic surgery.

A new systemic condition was diagnosed in 2 patients during follow-up. Cutaneous lupus erythematosus was diagnosed in 1 patient (based on histologic examination of a skin eruption) 6.2 years following surgery, and rheumatoid arthritis was diagnosed in the other 8 years following surgery (details of diagnosis not available). Given the length of time between the diagnosis of aortitis and the new systemic conditions, we analyzed these cases as cases of idiopathic aortitis. Neither of these patients had isolated aortitis as their initial diagnosis. The patient in whom cutaneous lupus erythematosus was diagnosed was reported to have died from a high-grade myelodysplastic syndrome (last follow-up was at $6.7 \mathrm{yr}$ ).

\section{Interpretation}

We identified 32 cases of idiopathic aortitis, 6 of which were further classified as isolated aortitis, among 684 patients over a 10.5 -year period at our institution. Additional aortic or branch vessel lesions were found in 16 of the 21 patients with complete imaging of the aortic branch vessels at baseline. Twelve of the 32 patients received perioperative treatment with glucocorticoids. During the mean follow-up period of 47.5 months, new radiographic lesions were identified in 5 of 12 patients. Three patients required additional vascular surgery, and a new systemic condition was diagnosed in 2; these outcomes did not seem to be affected by perioperative medical treatment.

The incidence of aortitis among aortic specimens in our series was $6.9 \%$, and the incidence of idiopathic aortitis was $4.7 \%$, comparable to rates of $2 \%-9 \%$ described in published retrospective series. ${ }^{10-12,17,18}$ Most cases of aortitis in our series were idiopathic, also consistent with the existing literature., ${ }^{3,11,12}$ The mean age of our patients with idiopathic aortitis was 66 years, within the reported range of 63-71 years in studies from 2000-2014. ${ }^{10-12,14}$ Our population had high prevalence rates of smoking, hypertension and other cardiovascular risk factors that are typically associated with noninflammatory aortic aneurysms; notably, a case-control study that compared features of idiopathic aortitis with noninflammatory aortic aneurysms identified current smoking as well as female sex as independent risk factors for idiopathic aortitis. ${ }^{19}$ Aortic aneurysms associated with idiopathic aortitis were limited to the thoracic aorta in 91\% of cases in our study, comparable to the rates seen by RojoLeyva and colleagues ${ }^{12}$ and Miller and colleagues ${ }^{10}$ (96\% in either study) and those reported for aortitis associated with systemic conditions including giant cell arteritis, ${ }^{1,20,21}$ rheumatoid arthritis $^{10,22}$ and systemic lupus erythematosus. ${ }^{6}$

Twelve (38\%) of our patients with idiopathic aortitis were treated with glucocorticoids, slightly higher than previously reported rates $(9 \%-34 \%))^{10-12,14}$ The higher rate in our study may be the result of increase in treatment with increased recognition of idiopathic aortitis over time. Investigators reporting lower rates of treatment, including Rojo-Leyva and colleagues $^{12}(21 \%)$ and Miller and colleagues ${ }^{10}(9 \%)$, reviewed cases of idiopathic aortitis dating back to 1977 and 1985, respectively, whereas the oldest cases included in our series were from 2003. Our rate of additional lesions found at baseline of $76 \%$ is similar to that of Liang and colleagues, ${ }^{11}$ who reported a rate of baseline radiographic lesions of $72 \%$ in their cohort of patients with noninfectious aortitis with an imaging rate of $89 \%$. Finally, our rate of new aortic or branch 
lesions among patients with complete follow-up imaging, $5 / 12(42 \%)$, is similar to the incidence rate of $44.6 \%$ reported in the study by Clifford and colleagues, ${ }^{14}$ in which routine follow-up imaging was done in all patients.

\section{Limitations}

Because of the retrospective nature of data collection in our study, the specific investigations, approach to management and subsequent monitoring were not standardized. As a result, only a fraction of included patients had measurement of inflammatory markers and complete imaging of the aorta and its brunches. Follow-up was inconsistent and in many cases was limited to focused assessments for postsurgical complications, which likely resulted in missed outcomes of interest such as diagnosis of a systemic inflammatory condition. The incompleteness of the data is likely further exacerbated by the fact that we limited data collection to $\mathrm{TOH}$ records, resulting in missing information pertaining to events (including investigations, clinical assessments, records of deaths and migration) that occurred outside our institution. We felt that these shortcomings were justified considering the significant increase in study complexity and time commitment that would be required to capture this information. Finally, although we believe that case ascertainment was good, given the completeness of the $\mathrm{TOH}$ pathology database and the use of broad search terms to identify entries pertaining to aortic specimen, our population represents a selected group of patients with a histologic diagnosis of aortitis following cardiovascular surgery at a major cardiovascular referral centre; thus, our conclusions are generalizable only to similar populations. Given that such referral centres are the main source of research activity in this area, it is not surprising that all of the currently available literature regarding idiopathic aortitis is based on review of similar populations.

\section{Conclusion}

We present detailed descriptions of clinical, laboratory and radiographic findings at baseline and follow-up in a series of patients with idiopathic aortitis, and review their corticosteroid and immunosuppressive therapies. Although no definitive guidelines can be made regarding the optimal approach to managing idiopathic aortitis, given the limitations of our study and the lack of other, good-quality evidence, several general recommendations can be proposed. On discovery of aortitis, detailed clinical and biochemical assessment is recommended to rule out an infectious cause or an associated systemic inflammatory condition. Full imaging of the aorta and its branches should be done to assess the extent of vascular involvement, as additional aortic and branch lesions appear to be common. In view of the lack of biomarkers of aortitis-related activity or damage, monito ring these cases should involve imaging studies; the best imaging modality and the optimal frequency of these studies are currently unclear. Similarly, the role of medical treatment (glucocorticoids and/or immunosuppressive agents) in idiopathic aortitis is controversial given the lack of evidence (also observed in our study) that such treatment changes clinical or radiographic outcomes; the general consensus is that isolated aortitis has a good prognosis and likely does not require medical treatment. Larger prospective and sys- tematic studies are required to address the many unanswered clinical questions regarding idiopathic aortitis and to allow formulation of more definitive recommendations.

\section{References}

1. Gornik HL, Creager MA. Aortitis. Circulation 2008;117:3039-51

2. Lie JT. Aortic and extracranial large vessel giant cell arteritis: a review of 72 cases with histopathologic documentation. Semin Arthritis Rheum 1995;24: 422-31.

3. Svensson LG, Arafat A, Roselli EE, et al. Inflammatory disease of the aorta: patterns and classification of giant cell aortitis, Takayasu arteritis, and nonsyndromic aortitis. 7 Thorac Cardiovasc Surg 2015;149(Suppl 2):S170-5.

4. Sato EI, Lima DN, Espirito Santo B, et al. Takayasu arteritis. Int 7 Cardiol 2000;75:S163-6.

5. Slobodin G, Naschitz JE, Zuckerman E, et al. Aortic involvement in rheumatic diseases. Clin Exp Rheumatol 2006;24:S41-7.

6. Guard RW, Gotis-Graham I, Edmonds JP, et al. Aortitis with dissection complicating systemic lupus erythematosus. Pathology 1995;27:224-8.

7. Tucker CR, Fowles RE, Calin A, et al. Aortitis in ankylosing spondylitis: early detection of aortic root abnormalities with two dimensional echocardiography. Am 7 Cardiol 1982;49:680-6.

8. Jackman JD, Radolf JD. Cardiovascular syphilis. Am 7 Med 1989;87:425-33.

9. Cargile JS, Fisher DF, Burns DK, et al. Tuberculous aortitis with associated necrosis and perforation: treatment and options. 7 Vasc Surg 1986;4:612-5.

10. Miller DV, Isotalo PA, Weyand CM, et al. Surgical pathology of noninfectious ascending aortitis: a study of 45 cases with emphasis on an isolated variant. $\mathrm{Am}$ 7 Surg Pathol 2006;30:1150-8.

11. Liang KP, Chowdhary VR, Michet CJ, et al. Noninfectious ascending aortitis: a case series of 64 patients. 7 Rheumatol 2009;36:2290-7.

12. Rojo-Leyva F, Ratliff NB, Cosgrove DM 3rd, et al. Study of 52 patients with idiopathic aortitis from a cohort of 1,204 surgical cases. Arthritis Rheum 2000; 43:901-7.

13. Merkel PA. Noninfectious ascending aortitis: staying ahead of the curve [editorial]. 7 Rheumatol 2009;36:2137-40.

14. Clifford A, Arafat A, Idrees J, et al. Aortitis: outcomes from a cohort of 196 patients [abstract]. American College of Rheumatology Annual Meeting. Boston. Artbritis Rheum 2014;66:S1216-7.

15. Stone JR, Bruneval P, Angelini A, et al. Consensus statement on surgical pathology of the aorta from the Society for Cardiovascular Pathology and the Association for European Cardiovascular Pathology: I. Inflammatory diseases. Cardiovasc Pathol 2015;24:267-78.

16. Jennette JC, Falk RJ, Bacon PA, et al. 2012 Revised International Chapel Hill Consensus Conference Nomenclature of Vasculitides. Arthritis Rheum 2013;65: $1-11$.

17. Kerr LD, Chang YJ, Spiera H, et al. Occult active giant cell aortitis necessitating surgical repair. 7 Thorac Cardiovasc Surg 2000;120:813-5.

18. Pacini D, Leone O, Turci S, et al. Incidence, etiology, histologic findings, and course of thoracic inflammatory aortopathies. Ann Thorac Surg 2008;86: 1518-23.

19. Chowdhary VR, Crowson CS, Liang KP, et al. Cardiovascular risk factors and acute-phase response in idiopathic ascending aortitis: a case control study. Arthritis Res Ther 2009;11:R29.

20. Nuenninghoff DM, Hunder GG, Christianson TJH, et al. Incidence and predictors of large-artery complication (aortic aneurysm, aortic dissection, and/or large-artery stenosis) in patients with giant cell arteritis: a population-based study over 50 years. Arthritis Rheum 2003;48:3522-31.

21. Loricera J, Blanco R, Hernandez JL, et al. Non-infectious aortitis: a report of 32 cases from a single tertiary centre in a 4-year period and literature review. Clin Exp Rheumatol 2015;33(Suppl 89):S19-31.

22. Gravallese EM, Corson JM, Coblyn JS, et al. Rheumatoid aortitis: a rarely rec ognized but clinically significant entity. Medicine (Baltimore) 1989;68:95-106.

Affiliations: Division of Rheumatology (Murzin, Milman), Department of Medicine, University of Ottawa; Department of Pathology and Laboratory Medicine (Belanger, Veinot), The Ottawa Hospital; Department of Clinical Epidemiology (Milman), Ottawa Hospital Research Institute, Ottawa, Ont.

Contributors: All of the authors conceived of and designed the study. Diane Murzin and Eric Belanger obtained the data, and Diane Murzin and Nataliya Milman analyzed and interpreted the data and drafted the manuscript. All of the authors contributed to manuscript revision, approved the final version to be published and agreed to act as guarantors of the work.

Supplemental information: For reviewer comments and the original submission of this manuscript, please see www.cmajopen.ca/content $/ 5 / 2$ / E483/suppl/DC1 